\title{
Young Generation Attitudes and Awareness Towards the Implementation of Smart Card in Bahrain: An Exploratory Study
}

\author{
${ }^{1}$ Adel Ismail Al-Alawi and ${ }^{2}$ Mohammed Ahmed Al-Amer \\ ${ }^{1}$ University of Bahrain, College of Information Technology \\ Department of Management Information Systems, P.O. Box 32038, Kingdom of Bahrain \\ ${ }^{2}$ Central Informatics Organization, P.O. Box 5835, Kingdom of Bahrain
}

\begin{abstract}
SmartCards are one of the latest additions to the continuing list of advancements and innovations in the world of information and communication technology. A SmartCard resembles in size and shape to a normal credit card or bank ATM card, with a microprocessor chip implanted into the plastic card. These cards are used not just as identity cards, like the earliest versions of such cards, but hold a relatively huge amount of editable information including the card holder's bank data, epurse, finger print, health record, blood type, traffic and license details and other such vital information. The purpose of this study was to present a general overview of SmartCards, a brief history, features and applications of SmartCards and the introduction of SmartCards in the Kingdom of Bahrain. This study collects some information about the features and related issues regarding the SmartCards which are to be issued to the public. A total of 513 questionnaires were distributed to students of the University of Bahrain. The questions asked included questions to check the acceptance of the people to replace their current cards with a SmartCards and their awareness of the new National SmartCard in Bahrain. It also evaluates the efforts taken by the government to create awareness among the public about the usage and features of the SmartCards.
\end{abstract}

Key words: Smart card, CPR, contactless cards, encryption, digital cash, national smart card (NSC), biometrics, Bahrain

\section{INTRODUCTION}

The Kingdom of Bahrain has taken its careful steps to plunge into the global information age. The Kingdom has since long held the e-Bahrain vision. Today it encompasses the convenience of all residents accessing government services and information electronically wherever and whenever they choose.

The current card, Central Population Registration card (CPR) is already widely used as a proof of identity when applying for government or private sector services. One of the integral elements of the e-Bahrain project is the National Smart Card (NSC) Project. This NSC will be the key mechanism for communication between the government and its residents.

$\mathrm{In}^{[1]}$ a SmartCard is defined as: "A plastic creditcard-sized transaction card that contains a microprocessor chip. The International Standards Organization (ISO) has defined the smart card more formally in ISO Standard 7816". The microprocessor is under a gold contact pad on one side of the card. Think of the microprocessor as replacing the usual magnetic stripe on a credit card or debit card.

This study provides a broad overview of the processes involved in launching a multi application program and describes some of the initial and future services that issuers, and personalization of multipurpose SmartCards. Also it highlights the awareness of residents and efforts that have been taken by Central Informatics Organization (CIO) to educate residents regarding the introduction of NSC in the Kingdom of Bahrain. The project is expected to be fully rolled out during 2006; a few months away from this study.

This research collects some information about the features and related issues regarding the SmartCards which are to be issued to the public. It also evaluates the efforts taken by the government to create awareness among the public about the usage and features of the SmartCards. The study also provides information related to the inception of NSC in the Kingdom of Bahrain, which explains its features, the awareness of residents. Therefore the following issues have been taken into consideration.

* Why the NSC in the Kingdom of Bahrain?

* What efforts does the CIO provide to the public regarding the NSC?

* Drawbacks of NSC

* The awareness of residents about the launching of NSC in the Kingdom of Bahrain

* General issues about NSC

* Technical Issues

* NSC security

SmartCards are one of the latest additions to the continuing list of advancements and innovations in the 
world of information technology. A SmartCard is a similar to a plastic card but has a microprocessor embedded into it which can store data. It can be read and processed and can provide information to authenticated users ${ }^{[2]}$. The most important feature being the capability to store all information on a single cards and facilitating the sharing of common information and reducing the number of cards and data and work redundancy.

The storage of the data can be either on a memory or a microprocessor. The memory merely stores data which can be read. The microprocessor provides addition features like adding, deleting and editing the information with built-in security. The interfaces are of two types: Contact and Contactless. The Contactless Cards do not require physical contact with the reader but enable communication with the reader through radio frequency and has an embedded transmitter ${ }^{[2,3]}$.

Working of SmartCards: Businesses and governments can cope with the dynamic environment in the modern world with the support of SmartCards. The volatility in the environment calls for advanced security and data protection. The modern SmartCard is embedded with a microprocessor. The reader sends commands to the microprocessor using a standard like ISO 7816. These standards define command formats in great details. The reader then can read (sometimes write and edit) data on the cards ${ }^{[1,4]}$.

History of SmartCards: Table 1 shows the historical evolutions in the development of smart card technology in developed countries such as USA, Germany, France, Japan and European countries ${ }^{[2,3,5-7]}$.

In early 1990's, it became popular for health records and as an electronic purse in France and Germany, containing health records and a usable and refillable monetary value. ATMs and public telephones were used to add value into the card. An unsuccessful attempt was made during the Summer Olympic Games to use SmartCards in Australia and New York, but due to the lack of international standards and common technology, was shut down in $1998^{[4,6,7]}$.

With the advancement in the SmartCard technology and the common technology, the SmartCards will be replacing cash, ID cards, Passports, airline tickets, licenses, medical records for patients, credit cards, etc. This all is achievable due to increased memory capacity and better security using data encryption.

Major benefits of SmartCards: The consumers can benefit from the SmartCard features in many ways. Some of the features along with their benefits are listed in Table 2.

Some advantages of the SmartCard are its worldwide acceptance and built-in security ${ }^{[2,3]}$.
SmartCards are more secure and very difficult to fake. It also has a comparatively much larger storage than magnetic stripes and is compatible various devices such as mobiles phones, PCs and PDAs.

SmartCards in Bahrain: Gone are the days when one had to carry different cards for different purposes in one's wallet. There's good news for all those in Bahrain who carry many cards and keep wishing if they could carry 'one' instead of the many they have to carry. This wish has come true through the new "SmartCard System" that enables people to carry Passport and Central Population Register (CPR) details, as well as driving license, health and education records. This card also functions as an electronic purse.

Bahrain has already introduced Smart Card and plans a nation-wide roll out of the SmartCard notationwide by January 2006. With this Bahrain becomes one of the most advanced technological populations in the Gulf. The SmartCard is of the size of a credit card that has 32 to 64 kilobytes of memory, which can be upgraded with new applications whenever needed. The SmartCard enables public to enjoy access to government ministries and private sector companies to complete certain formalities without having to stand in queue $^{[8]}$. A conference and exhibition was held in January 2005 in view of the Kingdom's plan to issue SmartCard to the citizens and residents, organized by Bahrain Information Technology Society (BITS) and Central Informatics Organization (CIO). The Smart ID Card includes all personal information including epurse and fingerprint, the card holders will also be able to use the new SmartCard for financial transactions such as bill payments, money transfer, balance enquiry and cash withdrawals. It is also seen as a vital tool in fighting crime and terrorist groups. All in all, this system will help boost the economy of a country and will also help in cutting down on the time needed to complete certain jobs and will help in preventing tampering with official documents, such as forging passports $^{[9-11]}$.

Features of NSC: The SmartCards to be introduced in Bahrain possess some features which are very advanced compared to those used in other countries of the world. These cards will be similar in features to those being used in Singapore, Malaysia and Hong Kong. Some of the benefits of the new NSCs in Bahrain will include:

* Replace the existing government issued cards with a single multi-purpose card.

* Compliment the digital infrastructure for facilitating e-government.

* Provide the citizens with an easy access mechanism to government services.

* Support long-term planning of services such as housing, education, health...etc. 
Table 1 Historical Evolution in the Development of Smart Card Technology

\begin{tabular}{|c|c|c|c|c|}
\hline Year & & Patent / Inventor & Country & Description \\
\hline $1950 \mathrm{~s}$ & & $\begin{array}{l}\text { Diner's Club } \quad \text { VISA and } \\
\text { MasterCard }\end{array}$ & USA & $\begin{array}{l}\text { First plastic card to be used for payment purposes. The } \\
\text { payment permitted due to your "good name" rather than "cash". } \\
\text { The origin of the current day smart card. Innovation of } \\
\text { machine-readable card due to the cost pressures of fraud, } \\
\text { tampering, merchant handling, and bank charges. Embossed } \\
\text { card with a magnetic stripe }{ }^{[5]} \text {. }\end{array}$ \\
\hline 1968 & & Jurgen Dethloff and Helmut Grupp & German & $\begin{array}{l}\text { Applied the first Integrated Circuit Card (ICC) commonly } \\
\text { called chip card or smart card and filed a patent for using a } \\
\text { plastic as a carrier for microchip }{ }^{[2,5]} \text {. }\end{array}$ \\
\hline 1970 & & Dr Kunitaka Arimura & Japan & Filed the first patent on the concept of the Smart Card ${ }^{[2,5-7]}$ \\
\hline 1974 & & Roland Moreno & France & $\begin{array}{l}\text { Recorded the original patent for } \operatorname{ICC}^{[2,5-7]} \text {. Smart card } \\
\text { technology was used for payment for payphones and later for } \\
\text { debit cards. }\end{array}$ \\
\hline 1977 & & $\begin{array}{l}\text { Three manufacturers companies: } \\
\text { Bull CP8, SGS Thomson, and } \\
\text { Schlumberger }\end{array}$ & USA & Began developing the ICC product ${ }^{[7]}$ \\
\hline 1979 & & Motorola & France & $\begin{array}{l}\text { The French banking sector used the first single chip } \\
\text { microcontroller produced by Motorola }{ }^{[7]} \text {. However, according } \\
\text { to Clark }{ }^{[6]} \text { the specifications of the Smart Card was stated by } \\
\text { the French banks in } 1977 \text { and the prototype of the project } \\
\text { existed in } 1978\end{array}$ \\
\hline $\begin{array}{l}1982, \\
1984\end{array}$ & 1983 & Telecommunications & France & $\begin{array}{l}\text { First testing carried out in ICC by testing the serial memory } \\
\text { phone cards }{ }^{[7]} \text {. Clark }{ }^{[6]} \text { stated the adaptation of countrywide } \\
\text { used of Smart Card for a public telephone system, while }{ }^{[5]} \\
\text { stated that Postal and Telecommunication services (PTT) in } \\
1984 \text { effectively implemented IC in telephone cards. }\end{array}$ \\
\hline 1984 & & Banks & USA & ATM bank cards with chip successfully conducted ${ }^{[7]}$ \\
\hline 1986 & & Bull CP8 & USA & $\begin{array}{l}\text { Provided smart cards to the clients of some banks such as Bank } \\
\text { of Virginia, Maryland National Bank, First National Palm } \\
\text { Beach Bank and the Mall Bank } k^{[7]} \text {. }\end{array}$ \\
\hline 1986 & & Health Care PTT & France & $\begin{array}{l}\text { The implementation of the first application of smart card in } \\
\text { health sector }{ }^{[6]} \text { and millions of telephone smart cards were in } \\
\text { circulation }{ }^{[5]} \text {. }\end{array}$ \\
\hline 1987 & & $\begin{array}{l}\text { Department of Agriculture - Peanut } \\
\text { Marketing Card }\end{array}$ & USA & $\begin{array}{l}\text { The major implementation of smart card application in the } \\
\text { USA }^{[7]} \text {. }\end{array}$ \\
\hline 1991 & & $\begin{array}{l}\text { Wyoming Special Supplemental } \\
\text { Nutrition Program for Women, } \\
\text { Infants and Children }\end{array}$ & USA & Launched of the first Electronic Benefit Transfer (EBT) card $^{[7]}$. \\
\hline 1992 & & DANMONT & Denmark & Nationwide prepaid e-purse ${ }^{[7]}$. \\
\hline 1993 & & Telecarte (public phone) & France & The multifunction Smart Card was tested ${ }^{[7]}$. \\
\hline 1994 & & $\begin{array}{l}\text { Europay, MasterCard, and Visa } \\
\text { (EMV) German Government }\end{array}$ & Europe & $\begin{array}{l}\text { EMV issued a global smart } \text { card }^{[3,7]} \text { Issued } 80 \text { million health } \\
\text { smart cards for the citizen }{ }^{[7]} \text {. }\end{array}$ \\
\hline $\begin{array}{l}1995 \\
1996\end{array}$ & & Mobile Phone companies & $\begin{array}{l}\text { USA } \\
\text { USA }\end{array}$ & $\begin{array}{l}\text { Subscribers Charge calls with smart cards }{ }^{[7]} \text {. } \\
\text { Over } 1.5 \text { million VISACash issued The sponsorship between }\end{array}$ \\
\hline 1990 & & $\begin{array}{l}\text { Visa JavaCard and Multi- } \\
\text { Application Operating Systems. }\end{array}$ & USA & $\begin{array}{l}\text { two major credit cards companies; JavaCard and Multi- } \\
\text { Application operating system was developed as advanced } \\
\text { solutions for the problems of smart card interoperability }{ }^{[7]} \text {. }\end{array}$ \\
\hline 1998 & & $\begin{array}{l}\text { Government General Services } \\
\text { Administration and US Navy } \\
\text { Microsoft Heath services }\end{array}$ & $\begin{array}{l}\text { USA } \\
\text { France }\end{array}$ & $\begin{array}{l}\text { Implementation of nine-application smart card system with its } \\
\text { management system in the Smart Card Technology Center. } \\
\text { Window based operation systems for smart card was } \\
\text { announced. During this year France started to Pilot its smart } \\
\text { health card for its all citizens }{ }^{[7]} \text {. }\end{array}$ \\
\hline 1999 & & $\begin{array}{l}\text { Government General Services } \\
\text { Administration }\end{array}$ & USA & $\begin{array}{l}\text { The establishment of Smart Access Common ID Card program } \\
\text { as a contract vehicle for use by all Federal agencies to obtain a } \\
\text { standard }^{[7]} \text {. }\end{array}$ \\
\hline
\end{tabular}

Table 2: Features and benefits of the SmartCard

\begin{tabular}{ll}
\hline Feature & Benefit \\
\hline Security & $\begin{array}{l}\text { Encryption is used for security. PIN code is needed to access the information and data protected against unauthorized } \\
\text { people. Chip or microprocessor is tamper resistant. }\end{array}$ \\
Convenience & $\begin{array}{l}\text { SmartCards are easy to use and are portable. The use of common standard enables compatibility. A card can hold multiple } \\
\text { applications and its life is longer than a magnetic card. }\end{array}$ \\
Intelligence & $\begin{array}{l}\text { The smart card can hold 32KB of data, although newer versions have a much higher capacity. In addition to storage, there } \\
\text { is a capability of processing information and the information is editable and easily updateable. }\end{array}$ \\
\hline
\end{tabular}


* Provide accurate demographic information of population in Bahrain.

Initially this NSC will replace three existing cards issued government being the CPR, Driving License, and ID cards. In future it will expand to hold health, education, electricity information, labor services and epurse data. E-purse shall be configured to include the Bahrain E-Cash scheme. E-Cash allows for the storage of limited electronic cash on the card and can be used in electronic payment applications. The Kingdom of Bahrain National Smart Card (NSC) Project system infrastructure shall accept and transact E-Cash payments. This is a new service in Bahrain. All Bahraini citizens and residents who live and work in Bahrain must have a NSC just as the current CPR card. The smartcard will also be used as a travel document for Bahrainis to travel between Gulf Cooperation Council countries (Bahrain, Kuwait, Saudi Arabia, Qatar, United Arab Emirates and Oman).

Initially citizens and residents will access the information they need through automated kiosks equipped with card readers. In future citizens can access information through the Internet via their personal home computers. The address and occupation will be stored on the chip. This would extend the life of the NSC because most of the information printed on the card is fixed. However information that may change periodically would be better stored on the chip so that citizens would not have to change their NSC every time they changed their address or occupation.

For better security, the SmartCards will make use of biometrics. Biometrics refers to the electronic identification of a person based on his or her physiological or behavioral characteristics, in this case the uniqueness of each person's fingerprints. When accessing a biometrics enabled system, the captured minutiae are verified against the scanned fingerprint. This makes it one of the most secure access controls available.

The NSC contains unique features:

* Chip is temperature resistant.

* Information stored on the card can be PIN protected and/or read-write protected.

* Capable of performing data encryption.

* Capable of processing (not just storing) information.

* Post-issuance update of information and application.

Some cautious has to be taken for careful handling and avoiding damages to the NCR. Some of the ways to take care of the NCR are:

* Keep it in a safe carrying case (in your wallet or in a cardholder).

* Avoid exposing the card to excessive heat.

* Do not bend the card.

* Do not punch holes in your card.
* Do not tamper with any of the information or picture printed on the card.

* Do not wash the card or use it for any purpose it was not designed for ${ }^{[12]}$

\section{MATERIALS AND METHODS}

The researcher carried out an extensive survey by going to CIO to collect the required information needed to introduce the SmartCard System in the country. Interviews were held with the key SmartCard project members in the CIO. In order to acquire the information about the NSC in the Kingdom of Bahrain, the following methods were adopted:

Questionnaires were distributed to the student body in the college of Information Technology and the college of Business at the University of Bahrain. The students were made up of mostly juniors, sophomores and seniors. The purpose of selecting University students for the research was that the students are usually among the most informed group of people in the society and are aware of use of IT and they are the future decision makers of this country.

\section{RESULTS AND DISCUSSION}

A total of 600 questionnaires were distributed to morning and evening students of which 513 were returned with complete responses. This produced a response rate of $85 \%$. The questions asked included questions to check the acceptance of the people to replace their current cards with a SmartCards and their knowledge of the new NSC in Bahrain. It tries to evaluate the efforts exerted by the government to make aware the people of Bahrain about the new technology being introduced which the common people would use. It also tried to get some additional recommendations and comments from the students.

The questionnaire was divided into two sections. The first section included general information about the respondent and to differentiate among those who had some knowledge about SmartCards and the ones who had no information about the new NSC. The second section included the source of their knowledge, features expected, and an evaluation of the efforts of the government. Later for analysis purposes, both the types of questionnaires were sorted and analyzed.

The population of the questionnaire included almost equal number of males and females. About $88 \%$ of the respondents were Bahrainis and the rest being mostly from the GCC. Table $2 \mathrm{a}$ shows $72 \%$ of the respondents held less than 5 cards in their wallets. The rest who carried more than 5 cards were mostly employed males. 
Table 2a: Number of cards held

\begin{tabular}{lc}
\hline Number of Cards Held & Percentage of Respondents \\
\hline Less than 5 & 72 \\
5 to 7 & 19 \\
8 to 9 & 6 \\
More than 9 & 3 \\
\hline
\end{tabular}

Table 3 shows that $88 \%$ of the respondents were willing to replace their current cards with a single card. Reasons given by the ones who did not want to replace their cards with a single included:

* It would be more risky to loose a single card containing all your important information.

* They don't mind carrying a few cards.

* They feel that the number of cards shows their status.

Table 3: Respondents willing to replace multiple cards with a smartcard

\begin{tabular}{lc}
\hline $\begin{array}{l}\text { Willing to replace multiple cards } \\
\text { with a card }\end{array}$ & $\begin{array}{l}\text { Percentage of } \\
\text { Respondents }\end{array}$ \\
\hline Yes & 88 \\
No & 12 \\
\hline
\end{tabular}

Most of the respondents seldom lost their important cards, with $67 \%$ saying they never lost any important card.

The people of Bahrain (especially students), as proved by the survey are usually really interested in new technology. The survey shows that $84 \%$ of respondents fall in the category of people who are interested in new technologies.

A shocking result of the questionnaires was the percentage of respondents who had not even heard about the SmartCard technology or the NCS to be issued in Bahrain. Table 4 shows $37 \%$ of the respondents were unaware about the SmartCards, while the majorities $63 \%$ were well-informed.

Table 4: Awareness about SmartCard in Bahrain

\begin{tabular}{lc}
\hline Aware about SmartCards & Percentage of Respondents \\
\hline Yes & 63 \\
No & 37 \\
\hline
\end{tabular}

Table 5: Efforts of Government to educate people about NSC

Efforts of Government to educate Percentage of

people about NSC Respondents

Excellent 11

Good 31

Satisfactory

Not Satisfactory

20

38

The reason behind this large percentage of unaware students could be due to lack of effective steps taken by the government to educate the people about the new technology. Similar was the results of the evaluation of the government's efforts which showed that $58 \%$ of the aware people considered that the efforts of the government were less than adequate (Table 5). Another reason of the respondents answering that they were unaware about SmartCards could be the condition in the questionnaire stating:

"If your answer in the above question was "No", you can return the questionnaire without further completion."

Some of the respondents might have answered "No" just to avoid answering additional questions. But the analysis ignores this assumption and assumes that all respondents were honest in answering the questionnaires.

The most popular sources of information about SmartCards include newspapers, Internet and word of mouth. A few also mentioned that their source of knowledge about SmartCards was through their instructors or lecturers in the university. Figure 1 shows the sources of information about SmartCards.

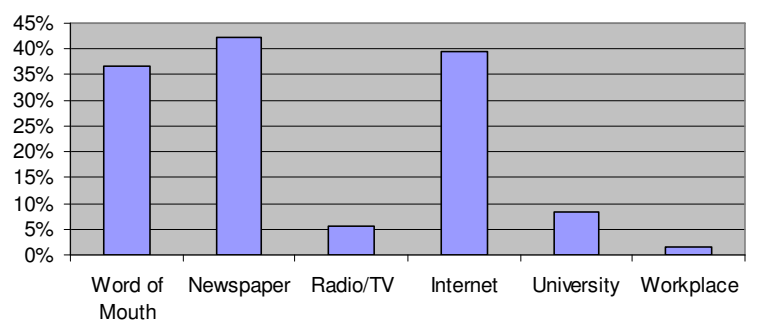

Fig. 1: Sources of information about SmartCards

The features to be included in the NSC as expected by the respondents, in accordance to popularity are:

* ID/Health

* Traffic

* Passport /Traveling document

* Credit Card

* Debit Card

* Employment

* Memberships

* Discount

* Resume

* Fingerprints

* Telephone cards

The survey shows that $76 \%$ of the respondents considered that having all information about an individual on a single card will create serious risk to privacy of the people. Another disappointing outcome of the survey was the small number of respondents who answered any essay answers like comments, recommendation or reasons. Only $11 \%$ of respondents made some comments and that too mostly not more than a few words.

The drawbacks to the NCS as mentioned by a few respondents included mainly privacy issues or increased risk incase of loss of the cards.

\section{CONCLUSION}

The Kingdom of Bahrain has lately announced that by 2006 , CPR cards will be replaced by SmartCards 
which could have features like ID, Passport, ATM card, e-purse etc. These cards will be issued to the public and necessary steps are being taken to educate people about the use of this new technology. The SmartCard system can be used to help people make their lives easy, and as the awareness about this system grows people will look forward to try this in future, and at the same time enjoy the various benefits that this system provides.

SmartCards help businesses evolve and expand their products and services in a changing global marketplace. The SmartCard provides maximum security and convenience and also provides data portability. The SmartCard when introduced will be highly successful in Bahrain as it carries more information than can be accommodated on a magnetic stripe card. It can make a decision as it has relatively powerful processing capabilities. SmartCards actually offer more security and confidentiality than other financial information or transaction storage vehicles, making it a perfect solution for E- commerce transactions.

\section{RECOMMENDATIONS}

As the Central Informatics Organization (CIO) is the first governmental organization in Bahrain to adapt and introduce the smart card; hence, they may face some problems while launching it. Smart Card creates changes in the society and organizations, some of these changes are manifest while others are invisible and these are more difficult to deal with.

One of the important things to be considered is to increase residents' awareness of the smart card and its advantages. The following recommendations should be taken into consideration in coming stages of launching the smart card.

* Develop a nation wide campaign to promote the new smart card for different community segments.

* Using newspapers, road banners, television, Internet and other medias to convey information about the card to the public.

* More press conferences and visit to schools and universities to enlighten the young generation to use the smart card.

* Providing guidelines for the card usage and advantages.

* The public has the full right to be informed of the card limitations or disadvantages. Along with these disadvantages, clear and trusted solutions to those limitations should be provided.

* Provide the public assurance that the smart card will not impose any threat to their privacy, and it will enhance the quality of services provided to them.

* Reconsideration the smartcard cost.

* Provide the services of issuing the cards in place of work in significant corporations, governmental organizations, private and public schools; and universities.

\section{REFERENCES}

1. NBS Technologies Inc., 2004. Smart Card Frequently Asked Questions. http://www.nbstech.com/solutions_faq.html

2. Dhar, S., 2005. Introduction to Smart Cards. http://www.rootshell.be/ dhar/downloads/SmartCa rds-Introduction.pdf

3. Al-Alawi, A.I. and N. Al-Quraishi, 2005. The Evolution of Smartcard and EMV Migration in Bahrain. Review of Business Information Systems, 9: 73-92.

4. Global Platform, 2000. A Primer to the Implementation of Smart Card Management and Related Systems, Global Platform, August, Version 1.0. http://www.globalplatform.org/documents/ supporting/Implementation_Primer_SCMS_v1_0.p df

5. Petri, S., 1999. An Introduction to Smart Cards part 1 of a Two-Part Series. http://www.opengroup.org/comm/the_message/ma gazine/mmv5n5/SmartCards.htm.

6. Clark, A.J., 1990. Smart Cards. http://www.primarykey.co.uk/Andy/Papers/smartc 02.pdf

7. Cardwerk, 2005. History of Smart Cards. http://www.cardwerk.com/smartcards/smartcard_hi story.aspx

8. Agence France Presse, 2004. Bahrain Plans Smart Card ID by June. Arab News, 5 Feb 2004. http://www.arabnews.com/?page $=4 \&$ section $=0 \&$ ar ticle $=39064 \& d=5 \& m=2 \& y=2004 \&$ pix=world.jpg \&category $=$ World

9. Bushehri, S., 2005. Bahrain Leads Gulf States in Smart Card Project. Arab News, 2 Feb 2005. http://www.arabnews.com/?page $=6 \&$ section $=0 \&$ ar ticle $=58400 \& \mathrm{~d}=2 \& \mathrm{~m}=2 \& \mathrm{y}=2005$

10. Bahrain Tribune, 2005. Smart card to boost GCC Unity. Bahrain Tribune News Paper, Published by Al-Ayam Press, 10th Jan., Bahrain.

11. Gulf News, 2003. Bahrain to issue national smart cards. 27 Aug 2003. http://www.atmmarketplace. com/cgi-bin/avantgo/avantgo_article.pl?id=16666

12. Un Published Publication from Central Informatics Organization (CIO), publications about smart card, Kingdom of Bahrain 2005. Search http://www.bahrain.gov.bh 